\title{
Maternal Adjustment and Maternal Attitudes in Adolescent and Adult Pregnant Women
}

\author{
Bárbara Figueiredo PhD*, Iva Tendais PhD Candidate, Cláudia C. Dias PhD Candidate \\ School of Psychology, University of Minho, Braga, Portugal
}

\section{A B S T R A C T}

Study Objective: This study analyzes differences between adolescent and adult pregnant women and the contribution of maternal age to maternal adjustment and maternal attitudes during pregnancy.

Design, Setting, and Participants: A sample of 398 Portuguese pregnant women (111 younger than 19 years) was recruited in a Portuguese Maternity Hospital and completed the Maternal Adjustment and Maternal Attitudes Questionnaire between the $24^{\text {th }}$ and $36^{\text {th }}$ weeks of gestation.

Main Outcome Measures: Maternal Adjustment and Maternal Attitudes Questionnaire ${ }^{1}$

Results: Adolescent pregnant women show lower maternal adjustment (poorer body image and worse marital relationship) and poorer maternal attitudes (more negative attitudes to sex) than adult pregnant women. When controlling for socio-demographics, age at pregnancy predicts poorer body image and more negative attitudes to sex, but not a worse marital relationship, more somatic symptoms or negative attitudes to pregnancy and the baby. A worse marital relationship was better predicted by living without the partner, and more somatic symptoms and negative attitudes to pregnancy and the baby was predicted by higher education.

Conclusion: Adolescent pregnant women show lower maternal adjustment and poorer maternal attitudes than adult pregnant women according to socio-demographics and unfavorable developmental circumstances.

Key Words: Adolescent mothers, Maternal adjustment, Maternal attitudes, Parenthood, Pregnancy, MAMA questionnaire

\section{Introduction}

Several difficulties have been associated with the transition to parenthood, particularly in adolescent mothers. An increase in both somatic symptoms (such as fatigue or sleep disruption) and psychological symptoms (such as anxiety or depression) has been documented., ${ }^{2,3}$ Teenage mothers seem to be particularly at risk of experiencing somatic and psychological symptoms during pregnancy and the postpartum period. ${ }^{4-12}$ A decrease in marital satisfaction and an increase in marital conflicts, in addition to a decrease in sexual desire, satisfaction, and activity, have been documented during pregnancy and the postpartum period; see Mitnick et al for a review. ${ }^{13}$ Furthermore, even more severe partner relationship difficulties have been noted in teenage mothers, such as higher rates of conflict and violence. ${ }^{14-19}$

Psychological adjustment during the transition to parenthood seems to be more difficult for adolescent mothers. This finding can be explained from a developmental perspective. The transition to parenthood is associated with biological, psychological, and social changes, particularly in a woman's identity, responsibilities, concerns, and significant relationships (with her partner and her family of origin). Several developmental tasks are involved in this life-span transition, namely maternal identity formation and

\footnotetext{
The authors indicate no conflicts of interest.

* Address correspondence to: Bárbara Figueiredo, PhD, School of Psychology, University of Minho, Campus de Gualtar, 4710-057 Braga, Portugal; Phone: +351253604656; fax: +351253604224

E-mail address: bbfi@psi.uminho.pt (B. Figueiredo).
}

acceptance of the baby as a separate person. ${ }^{20}$ The performance of these developmental tasks may be more difficult for adolescent mothers because they are encountering the challenges of adolescence and are likely ill-prepared for motherhood, a traditional marker of adulthood. Moreover, the transition to parenthood implies some changes that conflict with the positive resolution of adolescent developmental tasks (for example, proximity with the family of origin vs autonomy). In fact, adolescent mothers have been reported to demonstrate greater difficulty integrating the parental role as a positive part of their individual identity $^{21-23}$ and understanding the commitment that pregnancy requires. ${ }^{24-26}$ Additionally, adolescent pregnant women and mothers may have unrealistic expectations about infants ${ }^{27-29}$ and the support they will receive from others to take care of the child. ${ }^{30}$ They also have difficulty separating the infant's perspective from their own. ${ }^{28,31,32}$

Psychological adjustment during the transition to parenthood seems to be related to the mother's ability to adapt to multiple changes and to achieve the developmental tasks of the transition and neither adolescent mothers nor their proximal environment (the partner and family of origin) may be prepared to do so. Thus, not only for socio-demographic adversity (as explained in the next paragraph), but also due to developmental constraints, adolescent mothers may be at higher risk of psychological adjustment difficulties during the transition to parenthood. To develop efficient strategies to promote their psychological adjustment, adolescent mothers' developmental difficulties during the transition to parenthood must be better acknowledged, which is a goal of this study. 
Some developmental and socio-demographic circumstances have also been linked to difficulties in the transition to parenthood. Adolescent pregnancy and motherhood is highly associated with unfavorable developmental circumstances, for example a childhood history of physical abuse, ${ }^{42}$ as well as with unfavorable socio-demographic circumstances, such as unemployment, living without a partner, lower socioeconomic status, and lower educational level, ${ }^{43-45}$ also in Portugal. ${ }^{46}$ These adverse sociodemographic circumstances could explain both poor maternal adjustment and negative maternal attitudes in adolescent pregnant women.

Maternal adjustment (body image, somatic symptoms, and marital relationship) and maternal attitudes (to sex, pregnancy, and the baby) are significant components of a woman's psychological adjustment while transitioning to parenthood. Somatic symptoms were related to the mother's psychological adjustment both before and after delivery. ${ }^{33}$ In a previous study, somatic symptoms at pregnancy, such as nausea, vomiting, and fatigue, were associated to depression. ${ }^{33}$ A negative body image was associated with more depressive symptoms $\mathrm{s}^{34,35}$ and weight/shape concerns predicted postpartum depression, particularly in adolescent mothers. ${ }^{36}$ The Maternal Adjustment and Maternal Attitudes (MAMA) questionnaire has been successfully used in several empirical studies, measuring maternal adjustment and maternal attitudes. The MAMA questionnaire has shown that pregnant women who report more somatic symptoms also report more obstetrical problems at delivery. ${ }^{37}$ Pregnant women with poorer attitudes toward their partner, their pregnancy, and their baby display higher rates of postpartum depressive symptoms. ${ }^{38,39}$ Mothers with better attitudes to pregnancy and the baby are involved in healthier practices and adequate health care, ${ }^{40}$ whereas mothers with poorer attitudes to pregnancy and the baby classify their infant as more difficult. ${ }^{1}$ Moreover, mothers over 35 years old report fewer somatic symptoms and more positive perceptions of their bodies at late pregnancy than younger pregnant women, but they report more problems in their marital relationship and less positive attitudes to sex than their younger counterparts at 1 year postpartum. ${ }^{41}$ As such, the high reliability and external and predictive validity of the MAMA questionnaire results were shown in several studies. ${ }^{1,37-41}$

Differences between adolescent and adult pregnant women have been reported in terms both of lower maternal adjustment (with a particular risk of psychopathological symptoms, as noted) and of poor maternal attitudes. Adolescent pregnant women usually have a negative body image, ${ }^{47}$ as well as more negative attitudes to $\operatorname{sex}^{48}$ and less positive attitudes to pregnancy and the infant. ${ }^{49}$ However, socio-demographics have usually not been controlled when comparing adolescent with adult mothers. These are important aspects to consider in relation to maternal adjustment and maternal attitudes.

The literature has reported that variables other than age affect maternal adjustment and maternal attitudes during the transition to parenthood and these variables have been integrated in this study. For example, the lack of experience with children is significantly associated with worse maternal attitudes during pregnancy and the postpartum period. ${ }^{50-52}$ Women with lower education show worse psychological adjustment to pregnancy and the postpartum period and have less positive health practices during pregnancy, whereas more educated women present more somatic symptoms during early gestation. ${ }^{53-57}$ Women living without a partner demonstrate less positive attitudes to the infant and worse marital relationship than women living with a partner. ${ }^{58-62}$ Unemployed women show a higher incidence of postpartum depression. ${ }^{63-65}$

The present study aimed to analyze differences between adolescent and adult Portuguese pregnant women and the contribution of maternal age to maternal adjustment, as indicated by the mother's body image, somatic symptoms, and marital relationship, and to maternal attitudes to sex, pregnancy, and the baby. Pregnant women's parity, education, employment status, and household arrangement were considered possible confounders for the studied differences.

\section{Methods}

\section{Participants}

Participants consisted of 398 pregnant women with 24 to 36 weeks of gestation, age 13 to 44 years $($ mean $=24.8), 111$ (28\%) with less than 19 years. Nearly all participants were Portuguese nationals (94.5\%) and Caucasian (98.5\%). Most women were primiparous, lived with the partner, were employed with a manual occupation, and had less than grade 9 education. Almost one-fifth of the women reported to be smoking, but only $3.3 \%$ were having health problems. Adolescent pregnant women had lower education and higher unemployment, and were more likely than adult mothers to be living without the partner during pregnancy (see Table 1).

\section{Measures}

The Maternal Adjustment and Maternal Attitudes questionnaire (MAMA) was specifically designed by Kumar et $\mathrm{al}^{1}$ to assess maternal adjustment and maternal attitudes during pregnancy and after delivery. This is a selfadministered questionnaire composed by 60 items, measuring mother's body image, somatic symptoms, marital relationship, attitudes to sex and attitudes to the pregnancy and the baby, with higher scores indicating higher level of maternal adjustment and positive attitudes. Sample questions include "Have you felt attractive?" (body image), "Have you got out of breath easily?" (somatic symptoms), "Has there been tension between you and your partner?" (partner relationship), "Have you found your partner sexually desirable?" (attitudes to sex), "Have you been worrying that you might not be a good mother?" (attitudes to pregnancy and the baby). A principal component factor analysis revealed a similar factor structure to the original version in the Portuguese version: 5 subscales with 12 items each. The Portuguese version demonstrated also adequate reliability ( $\alpha=0.86$ and a split-half coefficient of 0.87$).{ }^{66}$ 
Table 1

Socio-Demographics and Health Conditions

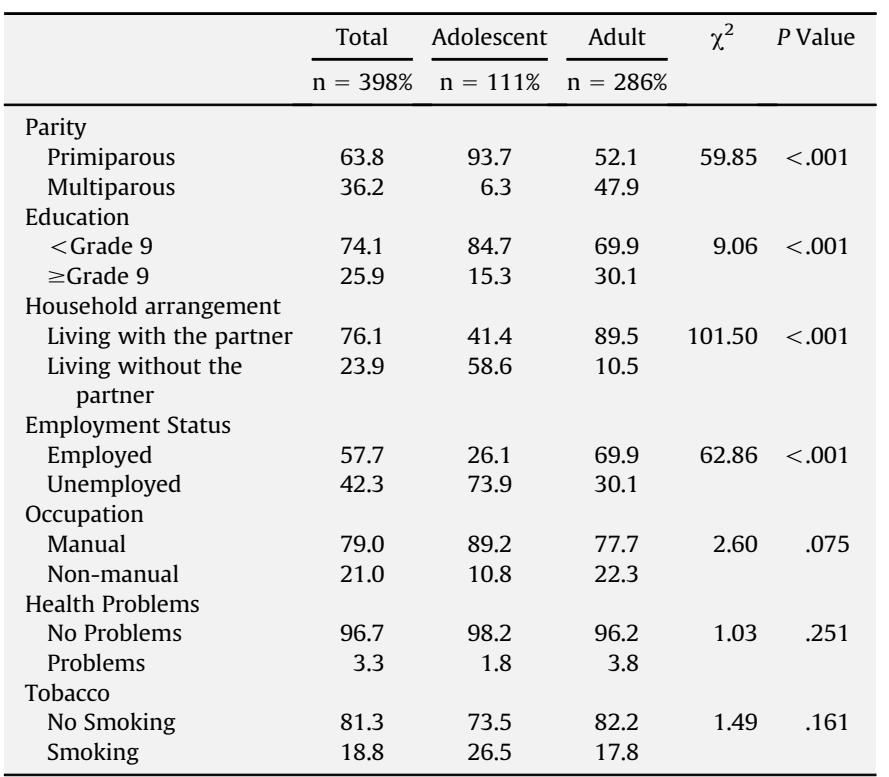

Procedures

This study received ethical approval from the Maternity Hospital Ethical Commission. Participants were contacted at the antenatal outpatient obstetric unit of a Public Maternity Hospital (Porto, Portugal) before their routine medical appointment at 24-36 weeks of gestation. Over 1 year, 1 day a week, on the specific weekday that pregnant adolescent women were scheduled, all the pregnant women attending to the antenatal outpatient obstetric unit were invited to participate in the study. Pregnant women with multiple gestations and with medical and/or obstetric complications were excluded. Those who agreed in participating were asked to sign an informed consent ( $80 \%$ percent of those approached). Women were interviewed to collect socio-demographic data after their medical appointment, and were then asked to complete the Portuguese version of the MAMA questionnaire, in an exam room at the Hospital. The questionnaires were filled in anonymously and confidentiality was guaranteed.

\section{Statistical Analysis}

Chi-square tests with Fisher exact test were used to assess group differences regarding parity, education, employment status and household arrangement, occupation, health problems, and tobacco consumption. Multivariate analysis of variance (MANOVAs) followed by univariate $\mathrm{F}$ tests were performed to examine adolescent and adult group differences across the MAMA subscales (dependent variables). Separate MANOVAs were also performed to explore differences in MAMA subscales results according to parity, education, employment, and household arrangement during pregnancy (socio-demographic variables). Independent sample $t$ tests were used to examine differences between the groups in MAMA total scores. From these analyses, variables with multivariate effect on MAMA subscales were selected. Potentially significant interactions between age group and previously listed variables (from now on designated by socio-demographic variables) that demonstrated multivariate effects on MAMA subscales were further examined in separate 2-factor MANOVAs.

To determine the contribution of maternal age to MAMA subscales and total scores separate hierarchical multiple regression analyses (blockwise forced entry) were conducted with the potential confounders in Block 1 (parity, education, marital, and employment status) and maternal age entered in Block 2.

\section{Results}

Differences in Maternal Adjustment and Maternal Attitudes between Pregnant Adolescent and Adult Women

Multivariate analysis of variance (MANOVA) revealed significant group differences between adolescent and adult pregnant women on MAMA subscales (Wilks $\Lambda=.89$, $\mathrm{F}(5,385)=9.40, P<.001)$. Univariate tests indicated that adolescent pregnant women show less positive body image, worse marital relationship and more negative attitudes to sex than adult pregnant women. No differences were found between the groups in somatic symptoms and attitudes to pregnancy and the baby subscales. Significant mean differences were found in MAMA total score with adolescent pregnant women having lower score than adults (See Table 2).

Differences in Maternal Adjustment and Maternal Attitudes between Pregnant Adolescent and Adult Women according with Socio-Demographics: Parity, Education, Employment Status, and Household Arrangement

Significant group differences were also found on overall MAMA subscale results according to parity (Wilks $\Lambda=.97$, $\mathrm{F}(5,386)=2.62, P<.05$ ], education [Wilks $\Lambda=.97$, $\mathrm{F}(5,385)=2.69, P<.05$ ), employment (Wilks $\Lambda=.95$, $\mathrm{F}(5,385)=4.31, P=.001)$ and household arrangement (Wilks $\Lambda=.92, \mathrm{~F}(5,385)=6.59, P<.001$ ), as revealed by separate MANOVAs. Subsequent univariate analysis revealed that primiparous, unemployed, and women living

Table 2

Differences between Adolescent and Adult Pregnant Women on MAMA Subscales and Total Score

\begin{tabular}{|c|c|c|c|}
\hline & \multicolumn{2}{|c|}{ Age } & \multirow[t]{3}{*}{$F_{(389)}$} \\
\hline & Adolescent $(\mathrm{n}=107)$ & Adult $(\mathrm{n}=284)$ & \\
\hline & $\mathrm{M}(\mathrm{SD})$ & $\mathrm{M}(\mathrm{SD})$ & \\
\hline Body Image & $33.22(4.89)$ & $35.08(4.53)$ & $12.53^{\dagger}$ \\
\hline Somatic Symptoms & $32.83(4.54)$ & $32.57(5.25)$ & 5.17 \\
\hline Marital Relationship & $38.69(5.75)$ & 40.65 (4.99) & $11.00^{*}$ \\
\hline Attitudes to Sex & $33.08(5.27)$ & $39.96(5.27)$ & $41.94^{\dagger}$ \\
\hline $\begin{array}{l}\text { Attitudes to Pregnancy } \\
\text { and Baby }\end{array}$ & $32.93(3.57)$ & $33.38(3.15)$ & 15.20 \\
\hline Total & $170.77(15.91)$ & $178.64(15.60)$ & $\begin{array}{r}t_{(389)} \\
-4.43^{\dagger}\end{array}$ \\
\hline
\end{tabular}

MANOVA analyses were performed for MAMA subscales and t-tests for MAMA total score.

${ }^{*} P<.01$.

$\dagger P<.001$. 
without the partner had more negative attitudes to sex than multiparous, employed, and women living with the partner. Unemployed and women living without the partner reported a worse body image and marital relationship, as well as lower MAMA total results than employed and women living with the partner. Women with higher education showed worse attitudes to pregnancy and the baby compared with women with lower education (see Table 3).

Examining the Contribution of Maternal Age to Maternal Adjustment and Maternal Attitudes, When Controlling for SocioDemographics: Parity, Education, Employment Status, and Household Arrangement

When maternal age ( $<19$ vs $\geq 19$ years old) was added to the model of body image subscale (Block 2 ), the model remained significant, and $5.0 \%$ of the variance was explained. In this model, being primiparous predicted more positive body image, whereas being adolescent predicted a less positive body image (see Table 4 ).

When maternal age ( $<19$ vs $\geq 19$ years old) was added to the model of somatic symptoms subscale (Block 2), the model was not significant $(P=.157)$. In this model, having a higher education level predicted more somatic symptoms ( $\beta=.118, P=.025$ ).

When maternal age ( $<19$ vs $\geq 19$ years old) was added to the model of marital relationship subscale (Block 2), the model remained significant, and $4.3 \%$ of the variance was explained. In this model, living without the partner predicted a worse marital relationship.

When maternal age ( $<19$ vs $\geq 19$ years old) was added to the model of attitudes to sex subscale (Block 2), the model remained significant, and $12.2 \%$ of the variance was explained. In this model, maternal age was the only significant predictor, with adolescent pregnant women having less positive attitudes to sex than adult.

When maternal age ( $<19$ vs $\geq 19$ years old) was added to the model of attitudes to pregnancy and the baby subscale (Block 2), the model was not significant. In this model, having a lower education predicted more positive attitudes to the pregnancy and the baby.

When maternal age ( $<19$ vs $\geq 19$ years old) was added to the model of MAMA total score, the model remained significant, and $6.1 \%$ of the variance was explained. In this model, being an adolescent pregnant woman predicted less positive maternal adjustment and maternal attitudes.

\section{Discussion}

The overall results show that being a pregnant adolescent woman contributes significantly to explaining lower maternal adjustment and poorer maternal attitudes during pregnancy when other confounding variables are controlled, specifically unemployment and household arrangement. When controlling for socio-demographics, age at pregnancy still predicts poorer body image, more negative attitudes to sex, and overall lower total MAMA results. A worse marital relationship is predicted by living without a partner, and more somatic symptoms and

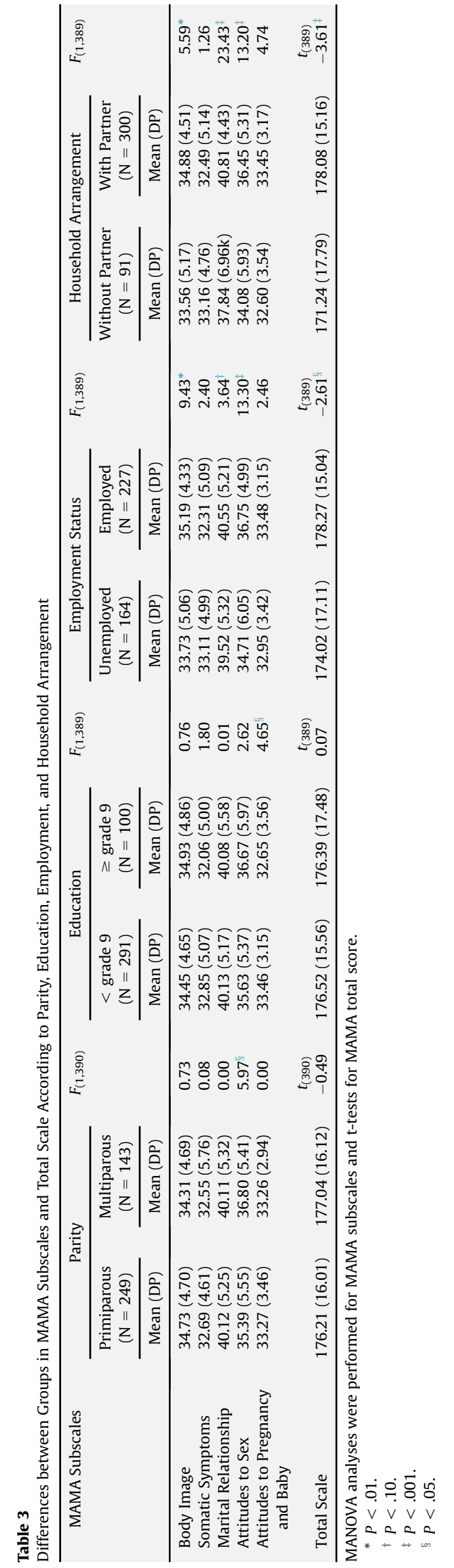


Table 4

Predictors of MAMA Subscales and Total Score

\begin{tabular}{|c|c|c|c|c|c|c|}
\hline Dependent Variables & Independent Variables & $R 2$ & $\Delta R 2$ & $F$ & $\beta$ & $t$ \\
\hline \multirow[t]{11}{*}{ Body Image } & Step 1 & .035 & - & $3.498^{\ddagger}$ & & \\
\hline & Primiparous & & & & .073 & 1.413 \\
\hline & $<$ grade 9 & & & & -.060 & -1.175 \\
\hline & Non-employed & & & & -.123 & $-2.342^{\dagger}$ \\
\hline & Living without the partner & & & & -.077 & -1.452 \\
\hline & Step 2 & .050 & $.015^{\dagger}$ & $4.034^{\ddagger}$ & & \\
\hline & Primiparous & & & & .123 & $2.223^{\dagger}$ \\
\hline & $<$ grade 9 & & & & -.031 & -0.588 \\
\hline & Non-employed & & & & -.088 & -1.614 \\
\hline & Living without the partner & & & & -.018 & -0.304 \\
\hline & Age $<19$ & & & & -.161 & $-2.449^{\dagger}$ \\
\hline \multirow[t]{11}{*}{ Marital Relationship } & Step 1 & .039 & - & 3.898 & & \\
\hline & Primiparous & & & & .014 & 0.276 \\
\hline & $<$ grade 9 & & & & -.038 & -0.746 \\
\hline & Non-employed & & & & -.064 & -1.204 \\
\hline & Living without the partner & & & & -.162 & $-3.030^{\ddagger}$ \\
\hline & Step 2 & .043 & .004 & $3.487^{\ddagger}$ & & \\
\hline & Primiparous & & & & .041 & 0.739 \\
\hline & $<$ grade 9 & & & & -.023 & -0.433 \\
\hline & Living without the partner & & & & -.043 & -0.790 \\
\hline & Non-employed & & & & -.130 & $-2.229^{\dagger}$ \\
\hline & Age $<19$ & & & & -.088 & -1.345 \\
\hline \multirow[t]{11}{*}{ Atittudes to Sex } & Step 1 & .078 & - & $8.181^{\S}$ & & \\
\hline & Primiparous & & & & -.126 & $-2.491^{\dagger}$ \\
\hline & $<$ grade 9 & & & & -.109 & $-2.193^{\dagger}$ \\
\hline & Non-employed & & & & -.132 & $-2.565^{\dagger}$ \\
\hline & Living without the partner & & & & -.110 & $-2.123^{\dagger}$ \\
\hline & Step 2 & .122 & $.044^{\S}$ & $10.731^{\$}$ & & \\
\hline & Primiparous & & & & -.041 & -.764 \\
\hline & $<$ grade 9 & & & & -.062 & -1.240 \\
\hline & Non-employed & & & & -.068 & -1.302 \\
\hline & Living without the partner & & & & -.008 & -0.148 \\
\hline & Age $<19$ & & & & -.278 & -4.402 \\
\hline \multirow[t]{11}{*}{ Atittudes to Pregnancy and the Baby } & Step 1 & .023 & - & $2.304^{*}$ & & \\
\hline & Primiparous & & & & .035 & 0.674 \\
\hline & $<$ grade 9 & & & & .105 & $2.053^{\dagger}$ \\
\hline & Non-employed & & & & -.059 & -1.118 \\
\hline & Living without the partner & & & & -.100 & $-1.880^{*}$ \\
\hline & Step 2 & .024 & .001 & 1.864 & & \\
\hline & Primiparous & & & & .042 & 0.755 \\
\hline & < grade 9 & & & & .109 & $2.078^{\dagger}$ \\
\hline & Non-employed & & & & -.054 & -0.975 \\
\hline & Living without the partner & & & & -.092 & -1.568 \\
\hline & Age $<19$ & & & & -.023 & -0.351 \\
\hline \multirow[t]{11}{*}{ MAMA total } & Step 1 & .041 & - & $4.133^{\ddagger}$ & & \\
\hline & Primiparous & & & & .014 & 0.268 \\
\hline & $<$ grade 9 & & & & -.015 & -0.289 \\
\hline & Non-employed & & & & -.095 & $-1.797^{*}$ \\
\hline & Living without the partner & & & & -.153 & -2.872 \\
\hline & Step 2 & .071 & $.003^{\ddagger}$ & $5.846^{5}$ & & \\
\hline & Primiparous & & & & .084 & 1.525 \\
\hline & $<$ grade 9 & & & & .026 & 0.500 \\
\hline & Non-employed & & & & -.044 & -0.805 \\
\hline & Living without the partner & & & & -.071 & -1.224 \\
\hline & Age $<19$ & & & & -.228 & -3.495 \\
\hline
\end{tabular}

$\mathrm{N}=$ 393. Multiple hierarchical regression, Blockwise Entry, Enter method.

${ }^{*} P<.10$.

$\dagger P<.05$.

$P<.01$.

$\S P<.00$.

negative attitudes to pregnancy and the baby are predicted by higher education.

Pregnant women younger than 19 years old, unemployed pregnant women, and pregnant women living without a partner report worse body image than pregnant women older than 19, employed pregnant women, and pregnant women living with a partner. When controlling for sociodemographics, maternal age remains a significant predictor of body image, as does parity. Being a pregnant woman younger than 19 years old predicts a less positive body image, whereas being primiparous predicts a more positive body image.

To our knowledge, there are no studies in the literature that address the differences between adolescent and adult pregnant women in terms of body image. However, the literature shows that adolescent pregnant women show dissatisfaction with their bodies during pregnancy ${ }^{47}$ and that older mothers present more positive perception of their bodies at late pregnancy than younger pregnant women. $^{41}$ 
Adolescence is characterized by normative challenges regarding body image, and most teenage girls are dissatisfied with their body image. ${ }^{67-69}$ Developmental issues may be involved in the adolescent mother's difficulty in developing a positive body image when pregnant. This topic may be a priority when working preventively with pregnant adolescent women to facilitate the transition to parenthood. $^{70-72}$

No significant differences were observed according to age at pregnancy in terms of somatic symptoms. Somatic symptoms were predicted by education, but the proposed socio-demographic model was not significant. Pregnant women with higher education presented more somatic symptoms. This finding is similar to previous findings that related higher maternal education to more vomiting ${ }^{57}$ and nausea $^{56}$ during gestation. However, somatic symptoms have also been found to be relatively independent of sociodemographic conditions in several studies. ${ }^{33,73,74}$

Pregnant women younger than 19 years old, unemployed pregnant women, and pregnant women living without a partner reported worse marital relationship than pregnant women 19 years or older, employed pregnant women, and pregnant women living with a partner. When controlling for socio-demographics, maternal age did not remain a significant predictor for marital relationship, and living without a partner predicted a worse marital relationship.

An extensive body of literature reports adolescent pregnant women/mothers' problems in close relationships, specifically with the partner/husband, congruent with the obtained results. A worse partner relationship has been found in adolescent pregnant women/mothers when compared with adult pregnant women/mothers, such as higher rates of conflicts and violence. ${ }^{14-19,62}$ However, when controlling for socio-demographics, the results show that a worse marital relationship is predicted by living without a partner. It is unsurprising that pregnant women living without a partner may have a worse marital relationship, which may be both a cause and a consequence. ${ }^{59,62}$

The partner relationship has been identified as a preventive issue to improve pregnant adolescent women's adequate transition to parenthood as well as to promote the infant's health and development. ${ }^{11,70,75}$ First, a positive relationship with the partner may improve the adolescent mother's psychological adjustment. ${ }^{76-80}$ Second, a positive relationship with the partner may benefit the adolescent mother's parenting..$^{81,82}$ Third, contact between the father and the infant has been associated with better child health and development outcomes. ${ }^{83,84}$ In fact paternity establishment rates for infants born from adolescent mothers are low, and even lower from infants born from younger adolescent mothers. ${ }^{85}$

Pregnant women younger than 19 years old, primiparous pregnant women, unemployed pregnant women, and pregnant women living without a partner showed poorer attitudes to sex than pregnant women 19 years or older, multiparous pregnant women, employed pregnant women, and pregnant women living with a partner. When controlling for socio-demographics, maternal age remained significant and the only predictor of attitudes to sex. Being a pregnant woman younger than 19 years old predicted worse attitudes to sex.
This finding is congruent with previous findings showing that adolescent pregnant women demonstrate more negative attitudes to sex than do adult pregnant women. ${ }^{46,48,86}$ Usually, adolescents have more negative attitudes to sex than adult women ${ }^{87}$ and problems regarding sexual intimacy have been largely reported in adolescents, ${ }^{88}$ particularly in adolescent pregnant women. ${ }^{14,48,86}$ Literature shows the need to consider a balance between promotion of adolescent autonomy and parental involvement regarding to sexual behaviors. ${ }^{89}$ As identified in this study, attitudes to sex may be another important focus of preventive work with pregnant adolescent women to facilitate an adequate transition to parenthood. These negative attitudes to sex may also be related to identified difficulties in implementing contraception strategies with adolescent mothers, which have been reported both before and after pregnancy. ${ }^{12,90-93}$ The priority of preventing another pregnancy during adolescence is the goal of most intervention programs with adolescent mothers. ${ }^{70,94,95}$

Attitudes to pregnancy and the baby do not differ significantly between adolescent and adult pregnant women and are not predicted by maternal age. Pregnant women with higher education have more negative attitudes to pregnancy and the baby. Having a higher education is the only significant predictor of worse attitudes to pregnancy and the baby.

The obtained results are congruent with previous findings that show no differences between adolescent and adult pregnant women in terms of maternal attitudes to pregnancy and the infant. ${ }^{96-98}$ This result is somewhat surprising, but it may be associated with the fact that adolescent pregnant women usually present more positive reports regarding expectations of motherhood and the baby; it has been suggested that these women have unrealistic expectations about these issues. ${ }^{27-30}$ Alternately, adolescent pregnant women's difficulties may not involve maternal attitudes to pregnancy and the baby. For example, despite the fact that adolescent pregnant women show a lower maternal antenatal attachment in the first pregnancy trimester, in the second and third pregnancy trimester there are no differences between adolescent and adult pregnant women. ${ }^{99}$ The results also corroborate other studies showing that more educated women show more negative attitudes to pregnancy and the infant. ${ }^{100}$

We can conclude that adolescent women show poorer maternal adjustment and maternal attitudes than adult pregnant women. At least part of this finding can be explained by age at pregnancy and may depend on developmental difficulties related to the transition to parenthood in adolescence, particularly in the case of body image and attitudes to sex. Socio-demographic conditions generally associated with adolescent pregnancy and motherhood, particularly unemployment and living without the partner, may aggravate the negative impact of being an adolescent pregnant woman in terms of maternal adjustment and maternal attitudes. We can also conclude that maternal adjustment and maternal attitudes depend on several factors, and age at pregnancy is only one of these factors. The results show that parity, socio-economic status, education, and household arrangement also predict some dimensions 
of maternal adjustment and maternal attitudes during pregnancy. Adolescent pregnant women show lower maternal adjustment (reporting poorer body image and worse marital relationship) and poorer maternal attitudes (reporting more negative attitudes to sex) than adult pregnant women, although these findings are only partially explained by age at pregnancy. When controlling for sociodemographics, age at pregnancy predicts poorer body image and more negative attitudes to sex. However, a worse marital relationship was better predicted by living without the partner, and more somatic symptoms and negative attitudes to pregnancy and the baby by higher education.

Controlling for socio-demographic conditions associated with adolescent pregnancy is one of the principal strengths of this study. Adolescent pregnant women experience specific risk conditions during the transition to parenthood. A strong point of this study is that it helps to clarify issues that should be considered when promoting adolescent pregnant women's transition to parenthood, such as improving body image, attitudes to sex, and the relationship with the partner. The consideration of these factors can contribute to adequate psychological preventive interventions regarding the specific needs of adolescent pregnant women/mothers. Assessing maternal adjustment (particularly the relationship with the partner) and maternal attitudes is a relevant issue in this process and may help to identify women with psychological difficulties, who may benefit from counseling and health promotion interventions during the transition to parenthood.

Although controlling for socio-demographics constitutes a novelty and strength of this study, few pregnant adolescent women were multiparous, employed, and living with a partner. Moreover, despite the large sample, the crosssectional nature is a limitation of the presented findings. Additional studies should analyze the stability of the observed differences on maternal adjustment and maternal attitudes between adult and adolescent women during the postpartum period. Furthermore, specificities of the cultural context must be considered when generalizing these results to other countries. Future research should also focus on specific risk and protective factors associated with maternal attitudes and maternal adjustment for adolescent and adult pregnant women/mothers.

\section{Acknowledgments}

This research was supported by FEDER Funds through the COMPETE (Programa Operacional Factores de Competitividade) and by National Funds through FCT (Fundação para a Ciência e a Tecnologia) under the project PTDC/SAU/ SAP/116738/2010.

\section{References}

1. Kumar R, Robson KM, Smith AM: Development of a self- administered questionnaire to measure maternal adjustment and maternal attitudes during pregnancy and after delivery. J Psychosom Res 1984; 28:43

2. Figueiredo B, Conde A: Anxiety and depression in women and men from early pregnancy to 3-months postpartum. Arch Womens Ment Health 2011; 14:247

3. Nylen KJ, Williamson JA, O'Hara MW, et al: Validity of somatic symptoms as indicators of depression in pregnancy. Arch Womens Ment Health 2013; 16: 203
4. Black AY, Fleming NA, Rome ES: Pregnancy in adolescents. Adolesc Med State Art Rev 2012; 23:123

5. McGuiness TM, Medrano B, Hodges A: Update on adolescent motherhood and postpartum depression. J Psychosoc Nurs Ment Health Serv 2013; 51:15

6. Figueiredo B, Pacheco A, Costa R: Depression during pregnancy and the postpartum period in adolescent and adult Portuguese mothers. Arch Womens Ment Health 2007; 10:103

7. Kingston D, Heaman M, Fell D, et al: Comparison of adolescent, young adult, and adult women's maternity experiences and practices. Pediatrics 2012; 129:e1228

8. Lanzi RG, Bert SC, Jacobs BK: Centers for the Prevention of Child Neglect: Depression among a sample of first-time adolescent and adult mothers. J Child Adolesc Psychiatr Nurs 2009; 22:194

9. Yozwiak JA: Postpartum depression and adolescent mothers: a review of assessment and treatment approaches. J Pediatr Adolesc Gynecol 2010 : 23:172

10. Hodgkinson SC, Colantuoni E, Roberts D, et al: Depressive symptoms and birth outcomes among pregnant teenagers. J Pediatr Adolesc Gynecol 2010; 23:16

11. Cox JE, Buman M, Valenzuela J, et al: Depression, parenting attributes, and social support among adolescent mothers attending a teen tot program. J Pediatr Adolesc Gynecol 2008; 21:275

12. Omar HA, Martin C, McElderry D: Screening for depression in adolescents: association with teen pregnancy. J Pediatr Adolesc Gynecol 2001; 14:129

13. Mitnick DM, Heyman RE, Smith Slep AM: Changes in relationship satisfaction across the transition to parenthood: A meta-analysis. J Fam Psychol 2009; 23: 848

14. Figueiredo B, Bifulco A, Pacheco A, et al: Teenage pregnancy, attachment style, and depression: a comparison of teenage and adult pregnant women in a Portuguese series. Attach Hum Dev 2006; 8:123

15. Gessner BD, Perham-Hester KA: Experience of violence among teenage mothers in Alaska. J Adolesc Health 1998; 22:383

16. Newman BS, Campbell C: Intimate partner violence among pregnant and parenting Latina adolescents. J Interpers Violence 2010; 26:2635

17. Parker B, McFarlane J, Soeken K: Abuse during pregnancy: effects on maternal complications and birth weight in adult and teenage women. Obstet Gynecol 1994; 84:323

18. Parker B, McFarlane J, Soeken $K$, et al: Physical and emotional abuse in pregnancy: A comparison of adult and teenage women. Nurs Res 1993; 42:173

19. Radestad I, Rubertsson C, Ebeling M, et al: What factors in early pregnancy indicate the mother will be hit by her partner during the year after childbirth? A nationwide Swedish survey. Birth 2004; 31:84

20. Cowan CP, Cowan PA: When partners become parents: The big life change for couples. New York, Basic Books, 1992

21. Bergamaschi SFF, Praça NS: The adolescent puerpera's experience of taking care of the newborn at home. [Article in Portuguese]. Rev Esc Enferm USP $2008 ; 42: 454$.

22. Thorman M: Attitudes of adolescents toward infants and young children. In: The At Risk Infant, Edited by Anastasiow HN, 1985, pp 41-49.

23. Wahn EH, Nissen E, Ahlberg BM: Becoming and being a teenage mother: how teenage girls in South Western Sweden view their situation. Health Care Women Int 2005; 26:591

24. Gilchrist LD, Schinke SP, Maxwell JS: Life skills counseling in preventing problems in adolescence. J Soc Serv Res 1987; 10:73

25. Moore MR, Brooks-Gun J: Adolescent parenthood. Handbook of Parenting. New Jersey, Erlbaum, 2002

26. Pungbangkadee R, Parisunyakul P, Kantaruksa K, et al: Experiences of early motherhood among Thai adolescents: perceiving conflict between needs as a mother and an adolescent. Thai J Nurs Res 2008; 12:70

27. Hanna B: Negotiating motherhood: the struggles of teenage mothers. J Adv Nurs 2001; 34:456

28. Hanson R: Initial parenting attitudes of pregnant adolescents and a comparison with the decision about adoption. Adolescence 1990; 25:629

29. Whitman TL, Borkowski JG, Keogh DA, et al: Interwoven lives: Adolescent mothers and their children. New Jersey, Erlbaum, 2001

30. Quinlivan JA, Luehr B, Evans SF: Teenage mother's predictions of their support levels before and actual support levels after having a child. J Pediatr Adolesc Gynecol 2004; 17:273

31. Atuyambe L, Mirembe F, Tumwesigye NM, et al: Adolescent and adult first time mothers' health seeking practices during pregnancy and early motherhood in Wakiso district, central Uganda. Reprod Health 2008; 5:13

32. Baranowski MD, Schilmoeller GL, Higgins BS: Parenting attitudes of adolescent and older mothers. Adolescence 1990; 25:781

33. Chou FH, Lin LL, Cooney AT, et al: Psychosocial factors related to nausea, vomiting, and fatigue in early pregnancy. J Nurs Scholarsh 2003; 35:119

34. DiPietro JA, Millet S, Costigan KA, et al: Psychosocial influences on weight gain attitudes and behaviors during pregnancy. J Am Diet Assoc 2003; 103:1314

35. Walker L, Timmerman GM, Kim M, et al: Relationships between body image and depressive symptoms during postpartum in ethnically diverse, low income women. Women Health 2002; 36:101

36. Birkeland R, Thompson JK, Phares V: Adolescent motherhood and postpartum depression. J Clin Child Adolesc Psychol 2005; 34:292

37. Eganhouse DJ: A comparative study of variables differentiating false labor from early labor. J Perinatol 1991; 11:249

38. Kumar R, Robson KM: A prospective study of emotional disorders in childbearing woman. Br J Psychiatry 1984; 144:35

39. Webster ML, Thompson JM, Mitchell E, et al: Postnatal depression in community cohort. Aust N Z J Psychiatry 1994; 28:42 
40. Dedee LS: Relationship among diet, nutrition beliefs, maternal attachment and adjustment to pregnancy in the second trimester. Diss Abst Int Sect B 1582; 1998:59

41. Windridge KC, Berryman JC: Maternal adjustment and maternal attitudes during pregnancy and early motherhood in women of 35 and over. J Reprod Infant Psychol 1996; 14:45

42. Adams JA, East PL: Past physical abuse is significantly correlated with pregnancy as an adolescent. J Pediatr Adolesc Gynecol 1999; 12:133

43. Mahavarkar SH, Madhu CK, Mule VD: A comparative study of teenage pregnancy. J Obstet Gynaecol 2008; 28:604

44. Omar K, Hasim S, Muhammad NA, et al: Adolescent pregnancy outcomes and risk factors in Malaysia. Int J Gynaecol Obstet 2010; 111:220

45. Vieira CL, Coeli CM, Pinheiro RS, et al: Modifying effect of prenatal care on the association between young maternal age and adverse birth outcomes. J Pediatr Adolesc Gynecol 2012; 25:185

46. Figueiredo B, Pacheco A, Costa R, et al: Adolescent motherhood: From risk circumstances to circumstances that beneficiate pregnancy adaptation. Int J Clin Hlth Psych 2006; 6:97

47. Stenberg L, Blinn L: Feelings about self and body during adolescent pregnancy. Fam Soc 1993; 74:282

48. Boxer AM: Adolescent pregnancy and parenthood in the transition to adulthood. In: Early Parenthood and Coming of Age in the 1990s. Edited by Rosenheim M, Testa MF. New Brunswick, NJ, Rutgers University Press, 1992, pp 46-54

49. Molina RC, Roca CG, Zamorano JS, et al: Family planning and adolescent pregnancy. Best Pract Res Clin Obstet Gynaecol 2010; 24:209

50. Fleming AS, Ruble DN, Flett G, et al: Postpartum adjustment in first-time mothers: Relations between mood, maternal attitudes and mother infant interactions. Dev Psychol 1988; 24:71

51. Melander HL: Experiences of fears associated with pregnancy and childbirth: a study of 329 pregnant women. Birth 2002; 29:101

52. Ngai F, Chan SW, Holroyd E: Chinese primiparous women's experiences of early motherhood: factors affecting maternal role competence. J Clin Nurs $2011 ; 20: 1481$

53. Gürel SA, Gürel H: The evaluation of determinants of early postpartum low mood: the importance of parity and inter-pregnancy interval. Eur J Obstet Gyn R B 2000; 91:21

54. Lindgren K: Relationships among maternal-fetal attachment, prenatal depression, and health practices in pregnancy. Res Nurs Health 2001: 24:203

55. Marcus SM, Flynn HA, Blow FC, et al: Depressive symptoms among pregnant women screened in obstetrics settings. J Womens Health (Larchmt) 2003; 12: 373

56. Meyer LC, Peacock JL, Bland J, et al: Symptoms and health problems in pregnancy: their association with social factors, smoking, alcohol, caffeine and attitude to pregnancy. Paediatr Perinat Epidemiol 1994; 8:145

57. Weigel MM, Caiza ME, Lascano Y, et al: Early pregnancy nausea and vomiting in a high-altitude Andean population. Int J Gynaecol Obstet 2000; 69:9

58. Aronson RS, Huston AC: The mother-infant relationship in single, cohabiting, and married families: a case for marriage? J Fam Psychol 2004: 18:5

59. Cairney J, Boyle M, Offord DR, et al: Stress, social support and depression in single and married mothers. Soc Psychiatry Psychiatr Epidemiol 2003; 38:442

60. Copeland DB, Harbaugh BL: Transition of maternal competency of married and single mothers in early parenthood. J Perinat Educ 2004; 13:3

61. Copeland D, Harbaugh BL: Differences in parenting stress between married and single first time mothers at six to eight weeks after birth. Issues Compr Pediatr Nurs 2005; 28:139

62. Pacheco A, Figueiredo B, Costa R: Quality of the relationship in significant persons: comparison between adolescent and adult pregnant women. Psicologia Teoria Prática 2009; 11:129

63. Mayberry LJ, Horowitz JA, Declercq E: Depression symptom prevalence and demographic risk factors among U.S. women during the first 2 years postpartum. J Obstet Gynecol Neonatal Nurs 2007; 36:542

64. Miyake Y, Tanaka K, Sasaki S, et al: Employment, income, and education and risk of postpartum depression: The Osaka Maternal and Child Health Study. J Affect Disord 2011; 130:133

65. Rubertsson C, Wickberg B, Gustavsson P, et al: Depressive symptoms in early pregnancy, two months and one year postpartum-prevalence and psychosocial risk factors in a national Swedish sample. Arch Women Ment Health 2005; 8:97

66. Figueiredo B, Mendonça M, Sousa R: Portuguese validation of the Maternal Adjustment and Maternal Attitudes (MAMA). Psicologia: Saúde Doenças 2004; 5:31

67. Clay D, Vignoles VL, Dittmar H: Body image and self-esteem among adolescent girls: Testing the influence of sociocultural factors. J Res Adolesc 2005; 15:451

68. Carlson Jones D: Body image among adolescent girls and boys: a longitudinal study. Dev Psychol 2004; 40:823

69. Thompson JK, Smolak L: Body image, eating disorders, and obesity in youth: Assessment, prevention, and treatment. Washington, DC, American Psychological Association, 2001

70. Pacheco A, Figueiredo B: Ser jovem, ser mãe e ser pai. Transição para a parentalidade de jovens mães e pais. Programa de intervenção em grupo. Lisbon, Editora Placebo, 2010
71. Story M: Promoting healthy eating and ensuring adequate weight gain in pregnant adolescents: issues and strategies. Ann N Y Acad Sci 1997; 817:321

72. Trad PV: Assessing the patterns that prevent teenage pregnancy. Adolescence 1999; $34: 221$

73. Paarlberg KM, Vingerhoets AJ, Passchier J, et al: Psychosocial factors as predictors of maternal well-being and pregnancy-related complaints. J Psychosom Obstet Gynaecol 1996; 17:93

74. Yonkers KA, Smith MV, Gotman N, et al: Typical somatic symptoms of pregnancy and their impact on a diagnosis of major depressive disorder. Gen Hosp Psychiatry 2009; 31:327

75. Social Exclusion Unit: Teenage pregnancy. Report presented to parliament by the Prime Minister by command of Her Majesty. London, Stationery Office Limited, 1999

76. Apfel NH, Seitz V: African American adolescent mothers, their families, and their daughters: A longitudinal perspective over twelve years. In: Leadbeater BJ, Way N, editors. Urban girls: Resisting stereotypes, creating identities. New York, New York University Press, 1996, pp 149-172

77. Davis AA, Rhodes JE: African American teenage mothers and their mothers: An analysis of supportive and problematic interactions. J Community Psychol $1994 ; 22: 12$

78. Rhodes JE, Ebert L, Meyers AB: Social support, relationship problems, and the psychological functioning of young African-American mothers. J Soc Pers Relat $1994 ; 11: 587$

79. Osborne LN, Rhodes JE: Sexual victimization among pregnant minority, adolescent mothers: An additional risk factor for adjustment difficulties. Am J Community Psychol 2001; 26:833

80. Piccinini CA, Rapoport A, Centenaro-Levandowski D, et al: Social support perceived by adolescent and adult mothers: From pregnancy to the infant's third month of life. PSICO 2002; 33:9

81. Gee CB, Rhodes JE: Adolescent mothers' relationships with their children's biological fathers: social support, social strain, and relationship continuity. Fam Psychol 2003; 17:370

82. Krishnakumar A, Black MM: Family processes within three-generation households and adolescent mothers' satisfaction with father involvement. J Fam Psychol 2003; 17:488

83. Jackson AP, Choi J, Franke TM: Poor single mothers with young children: mastery, relations with nonresident fathers, and child outcomes. Soc Work Res 2009; 33:95

84. Kalil A, Ziol-Guest K, Coley R: Perceptions of father involvement patterns in teenage-mother families: Predictors and links to mothers' psychological adjustment. Fam Relat 2005; 54:197

85. Murray AL, Rosengard C, Weitzen S, et al: Demographic and relationship predictors of paternity establishment for infants born to adolescent mothers. J Pediatr Adolesc Gynecol 2012; 25:322

86. Spear HJ: Personal narratives of adolescent mothers-to-be: Contraception, decision making, and future expectations. Public Health Nurs 2004; 21:338

87. Levy SR, Lampman C, Handler A, et al: Young adolescent attitudes toward sex and substance use: Implications for AIDS prevention. AIDS Educ Prev 1993; 5: 340

88. Jones MC, Furman W: Representations of romantic relationships, romantic experience and sexual behavior in adolescence. Pers Relatsh 2011; 18:144

89. Short MB, Wiemann C, Rosenthal SL: Participation of adolescent girls in a study of sexual behaviors: balancing autonomy and parental involvement. J Pediatr Adolesc Gynecol 2009; 22:105

90. Lemay CA, Cashman SB, Elfenbein DS, et al: Adolescent mothers' attitudes toward contraceptive use before and after pregnancy. J Pediatr Adolesc Gynecol 2007; 20:233

91. Glei DA: Measuring contraceptive use patterns among teenage and adult women. Fam Plann Perspect 1999; 31:73

92. Kershaw TS, Niccolai LM, Ickovics JR, et al: Short and long-term impact of adolescent pregnancy on postpartum contraceptive use: Implications for prevention of repeat pregnancy. J Adolesc Health 2003; 33:359

93. Raine TR, Foster-Rosales A, Upadhyay UD, et al: One-year contraceptive continuation and pregnancy in adolescent girls and women initiating hormonal contraceptives. Obstet Gynecol 2011; 117:363

94. Barnet B, Liu J, DeVoe M, et al: Home visiting for adolescent mothers: effects on parenting, maternal life course, and primary care linkage. Ann Fam Med 2007; 5:224

95. Black MM, Bentley M, Papas MA, et al: Delaying second births among adolescent mothers: a randomized, controlled trial of a home-based mentoring program. Pediatrics 2006; 118:e1087

96. Arenson JD: Strengths and self-perceptions of parenting in adolescent mothers. J Pediatr Nurs 1994; 9:251

97. Seamark CJ, Lings P: Positive experiences of teenage motherhood: a qualitative study. Br J Gen Pract 2004; 54:813

98. Williams C, Vines SW: Broken past, fragile future: personal stories of high-risk adolescent mothers. I Soc Pediatr Nurs 1999; 4:15

99. Rowe HJ, Wynter KH, Steele A, et al: The growth of maternal-fetal emotiona attachment in pregnant adolescents: a prospective cohort study. J Pediatr Adolesc Gynecol 2013; 26:327

100. Jaccard J, Dodge T, Dittus P: Do adolescents want to avoid pregnancy? Attitudes toward pregnancy as predictors of pregnancy. J Adolesc Health 2003; 33:79 